\title{
PREVALENCE OF UNCOLLECTED MEDICINES AT TWO HEALTH CENTERS IN BRUNEI
}

\author{
NUROLAINI KIFLI ${ }^{1 *}$, NAJWA RASHIDAH ISMAIL ${ }^{1}$, LAH KHENG CHUA ${ }^{2}$ \\ ${ }^{1}$ PAPRSB Institute of Health Sciences Universiti Brunei Darussalam, Brunei. ${ }^{2}$ Department of Pharmaceutical Services, Ministry of Health, \\ Brunei Darussalam, Brunei. Email: nurolaini.kifli@ubd.edu.bn
}

Received: 31 August 2020, Revised and Accepted: 17 November 2020

\section{ABSTRACT}

Objective: This study was designed to achieve a better knowledge of uncollected medicines at two health centers in Brunei.

Methods: Patients with prescriptions prepared at two community pharmacies but did not collect them within 1 week from March 2020 to April 2020 were included in this study. A telephone interview was conducted to discover why they did not collect their medicines.

Results: A total of 43 patients completed the study, giving a rate of $0.85 \%$ uncollected prescriptions. A proportion of $24 \%$ of the uncollected medicines was cardiovascular drugs, $35 \%$ belonged to participants who forgot to collect their medicines, and $14 \%$ were uncollected due to participants being too busy.

Conclusion: Further studies should be done to identify interventions that could decrease the number of uncollected medicines.

Keywords: Uncollected medicines, Prescription abandonment, Health Centers, Brunei.

(C) 2021 The Authors. Published by Innovare Academic Sciences Pvt Ltd. This is an open access article under the CC BY license (http://creativecommons.org/ licenses/by/4.0/) DOI: http://dx.doi.org/10.22159/ajpcr.2021v14i1.24782. Journal homepage: https://innovareacademics.in/journals/index.php/ajpcr

\section{INTRODUCTION}

Approximately $30-50 \%$ of patients do not take their prescribed medicines [1,2]. This non-adherence to medicine can lead to many problems, including an increase in morbidity and death rates [2]. One of the factors contributing to medicine non-adherence is prescription abandonment, which is defined as the inability of a patient to pick up their medicines from the pharmacy after they have been prepared [3]. Abandoned or unclaimed prescriptions are usually the terms used in research, but in this study, the term "uncollected medicines" will be widely used.

Several studies in other countries have shown different rates of abandoned prescriptions from $2.4 \%$ to $8.0 \%$ of total prepared prescriptions [4-8]. In terms of cost, one unclaimed prescription is estimated to be $\$ 11.50$ [8]. In a different study, the estimated cost is $\$ 37$ per unclaimed prescription [9]. Studies with different demographic groups show different results. Many studies suggest that the elderly have less uncollected medicines [6,10,11], although other studies suggest otherwise $[12,13]$. Results in regard to gender have also been inconsistent, where some studies discovered males to have more uncollected medicines and some found the opposite $[5,14,15]$.

Some of the repeating reasons for abandoned prescriptions include having a similar product at home, not knowing a prescription has been given, or simply because of inconvenience [5,6]. In general, the common drug classes of the uncollected medicines were psychiatric medicines, analgesics, contraceptives, and antibiotics [6].

Community pharmacies in Brunei have their own protocol in dealing with uncollected medicines (Fig. 1). The unclaimed medicines are placed in a designated "unclaimed prescription" container. Antibiotic suspensions are only mixed if the patient is waiting. If the patient is not waiting, the reconstituted antibiotics are used for another patient by removing the old label and affixing the correct label. Otherwise, they are kept in the refrigerator. Fridge items such as insulin injections are also kept in the refrigerator until the patient comes for collection.
For acute prescriptions, they are removed from the container 1 week later and a month later for chronic medications. Medicines are put back to the shelf for reuse after removing the dispensing label, making sure to check the batch number of unclaimed tablets or capsules before they are returned to the original bottles. Reconstituted preparations are discarded according to the disposal procedure if they become invalid. A pharmacist or dispenser must also perform a batch release in the Brunei Health Information Management System (Bru-HIMS). They are then to compile the prescriptions according to the date of prescription as an indication for work done and maintain a separate record for unclaimed medicines as an indication for the monthly number of unclaimed medicines.

To the best of our knowledge, uncollected medicines have yet to be studied in Brunei. Since there are limited available data, results from this study can help identify the characteristics of uncollected medicines and reasons why they are not collected. This information can also be used to acquire ways to reduce the rate of uncollected medicines, which, in turn, can reduce wasting of time and resources.

The objectives of this study are to: (1) quantify the number of uncollected medicines at two community pharmacies in Brunei, (2) determine the characteristics of uncollected medicines, (3) investigate why patients do not collect their medicines, and (4) assess ways on how the number of uncollected medicines can be reduced.

\section{METHODS}

This cross-sectional study was carried out from March 2020 to April 2020 at two health centers in Brunei. Data were extracted from Bru-HIMS, an electronic patient record system. Permission to conduct the study and obtain data was given by the Acting Director of Community Health Services and the Acting Director of Department of Pharmaceutical Services, Ministry of Health on March 5, 2020. The Institute of Health Sciences Research Ethics Committee (IHSREC) and Medical and Health Research Ethics Committee granted full ethical approval on March 7, 2020 (Reference number: UBD/ PAPRSBIHSREC/2020/8). 


\section{Study setting}

The study took place at two community pharmacies. Berakas Health Centre (BHC) was initially chosen as it is the busiest health center in the country, particularly because they offer extended hours [16]. However, due to the coronavirus disease (COVID-19) pandemic, their pharmacy services were temporarily diverted to Pengiran Anak Puteri Hajah Muta-Wakillah Hayatul Bolkiah Health Centre (PAPHMWHB HC), hence, the study site was moved as well. Similar to BHC, PAPHMWHB $\mathrm{HC}$ is one of the busiest local health centers. Both health centers offer comprehensive services including facilities such as flu clinic, maternal child health services, dental services, eye clinic, dietician clinic, and phlebotomy.

\section{Sample and criteria}

Participants were chosen by convenience sampling, where all patients with uncollected medicines were taken as potential subjects.

\section{Inclusion criteria}

Patients who do not collect their medicines 1 week after the prescription was filled at one of the study sites were included if they understood and spoke English or Malay languages.

\section{Exclusion criteria}

The exclusion criteria were as follows: (1) Patients who have collected their medicines within a week after the prescription were filled, (2) those with uncollected medicines at pharmacies other than the study sites, and (3) those who were not able to communicate in English or Malay languages.

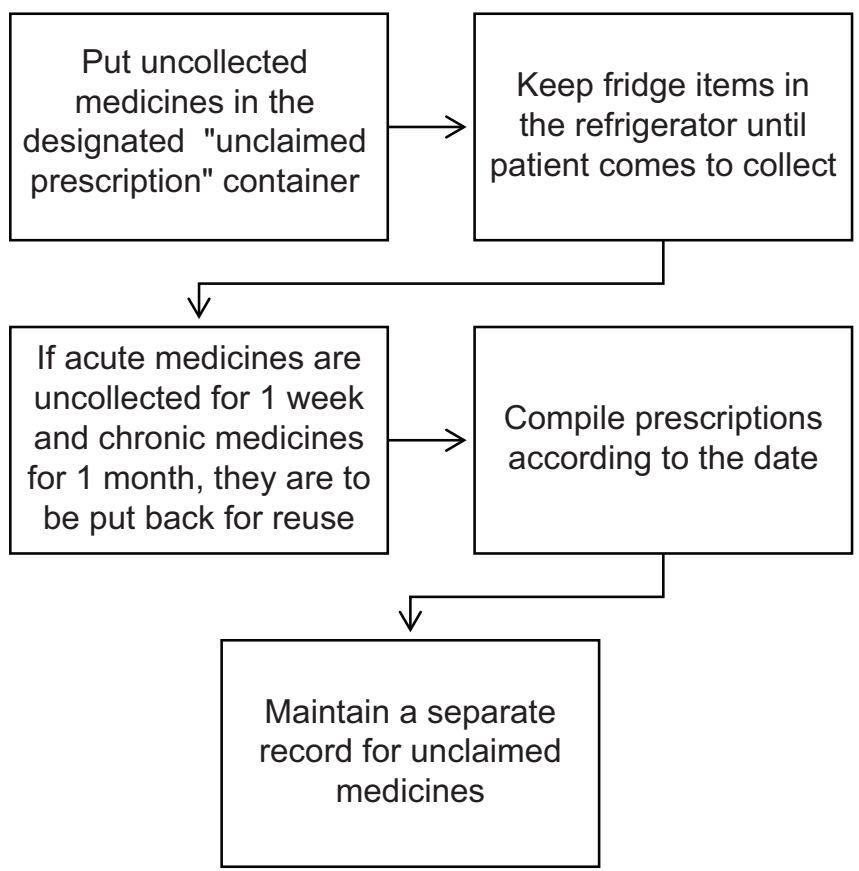

Fig. 1: Flowchart in clearing uncollected medicines

Table 1: Total number of prescriptions and items being dispensed from March to April 2020

\begin{tabular}{ll}
\hline Number of prescriptions or items & Data, n (\%) \\
\hline Number of prescriptions & \\
Dispensed & $12,159(99.15)$ \\
Uncollected & $104(0.85)$ \\
Total & $12,263(100 \%)$ \\
Number of items & \\
Dispensed & $46,779(99.35)$ \\
Uncollected & $307(0.65)$ \\
Total & $47,086(100 \%)$ \\
\hline
\end{tabular}

Uncollected medicines

In this study, the term "uncollected medicines" is defined as medicines that have not been collected for 7 days after the prescription was filled. At the 1-week mark, the phone numbers of the patients were retrieved from the database. They were called and explained about the study, and if they gave verbal consent to participate, they were asked for the reason for not picking up their medicines.

\section{Data collection}

Patient details needed to extract data were taken from the labels on the uncollected medicines. As mentioned previously, a short telephone interview was carried out by a trained staff with an interview guide provided. Apart from the reason for not collecting medicines, other information was taken from the database. These details included: (1) Demographic data of the patient, (2) date the prescription was filled, (3) type of condition (acute or chronic), and (4) details about the medicines (type, form, and cost).

\section{Data analysis}

The collected data were entered into a Microsoft Excel 2019 spreadsheet to be analyzed. Descriptive statistics were the main method used to summarize the characteristics of uncollected prescriptions and to assess the incidence of uncollected medicines. Analyses were conducted using R statistical software (version 3.6.2).

\section{RESULTS}

A total of 12,263 prescriptions were recorded during the study period, out of which 104 prescriptions were uncollected, as shown

Table 2: Overall characteristics of the participants and their prescriptions

\begin{tabular}{|c|c|}
\hline Characteristics of participants & Data, n (\%) \\
\hline Patients & 43 \\
\hline \multicolumn{2}{|l|}{ Age, years } \\
\hline $20-30$ & $7(16.3)$ \\
\hline $31-40$ & $11(25.6)$ \\
\hline $41-50$ & $14(32.6)$ \\
\hline $51-60$ & $8(18.6)$ \\
\hline $61-70$ & $3(7.0)$ \\
\hline Mean age $(\mathrm{SD})^{*}$ & $42.4(11.7)^{*}$ \\
\hline \multicolumn{2}{|l|}{ Sex } \\
\hline Male & $21(48.8)$ \\
\hline Female & $22(51.2)$ \\
\hline \multicolumn{2}{|l|}{ Type of condition } \\
\hline Acute & $17(39.5)$ \\
\hline Chronic & $26(60.5)$ \\
\hline \multicolumn{2}{|l|}{ Payment } \\
\hline Paying & $1(2.3)$ \\
\hline Non-paying & $42(97.7)$ \\
\hline \multicolumn{2}{|l|}{ Number of medicines } \\
\hline $1-2$ & $25(58.1)$ \\
\hline $3-4$ & $8(18.6)$ \\
\hline $5-6$ & $7(16.3)$ \\
\hline $7-8$ & $0(0)$ \\
\hline $9-10$ & $3(7.0)$ \\
\hline Median cost per prescription, BND\$ (IQR)** & $6(0.2-14.3)^{* *}$ \\
\hline \multicolumn{2}{|l|}{ Reason for uncollected medicines } \\
\hline Forgot about medicines & $15(34.9)$ \\
\hline Busy & $6(14.0)$ \\
\hline Afraid of current pandemic situation & $5(11.6)$ \\
\hline No transport to pharmacy & $4(9.30)$ \\
\hline Taken at another pharmacy & $4(9.30)$ \\
\hline Lost queue number & $2(4.65)$ \\
\hline In quarantine & $2(4.65)$ \\
\hline Lazy to collect medicines & $2(4.65)$ \\
\hline Queue at pharmacy is too long & $1(2.33)$ \\
\hline Prescription discontinued & $1(2.33)$ \\
\hline Bought own OTC medicine & $1(2.33)$ \\
\hline
\end{tabular}

**IQR is a measure of statistical dispersion, being equal to the difference between $75^{\text {th }}$ and $25^{\text {th }}$ percentiles 


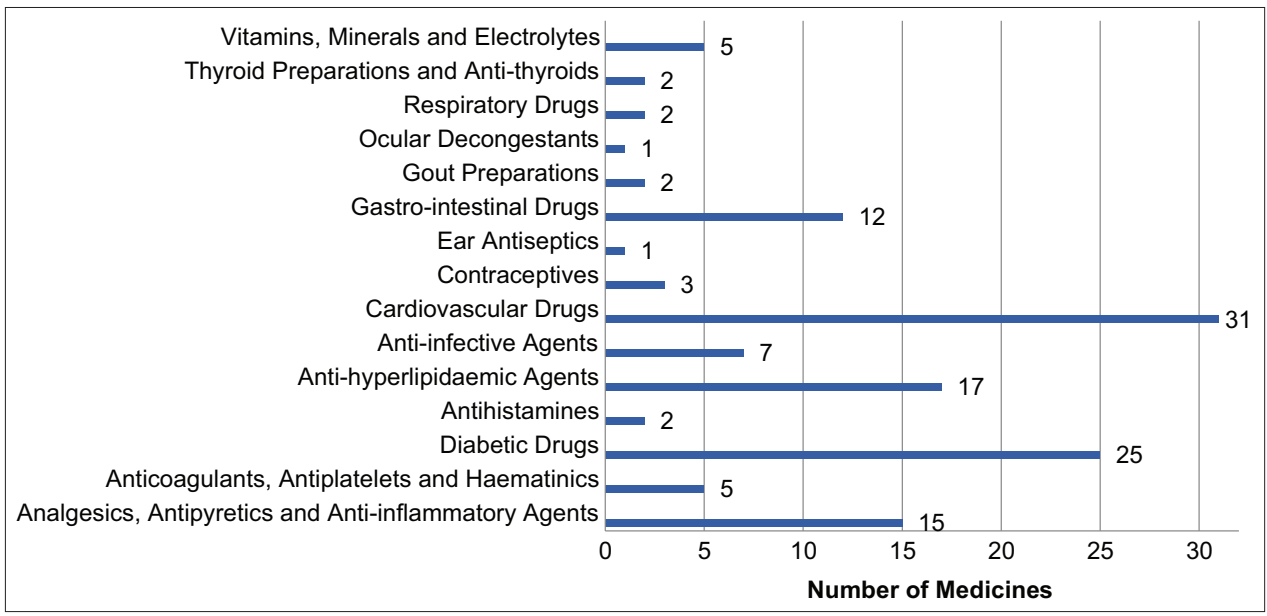

Fig. 2: Uncollected medicines by their drug category

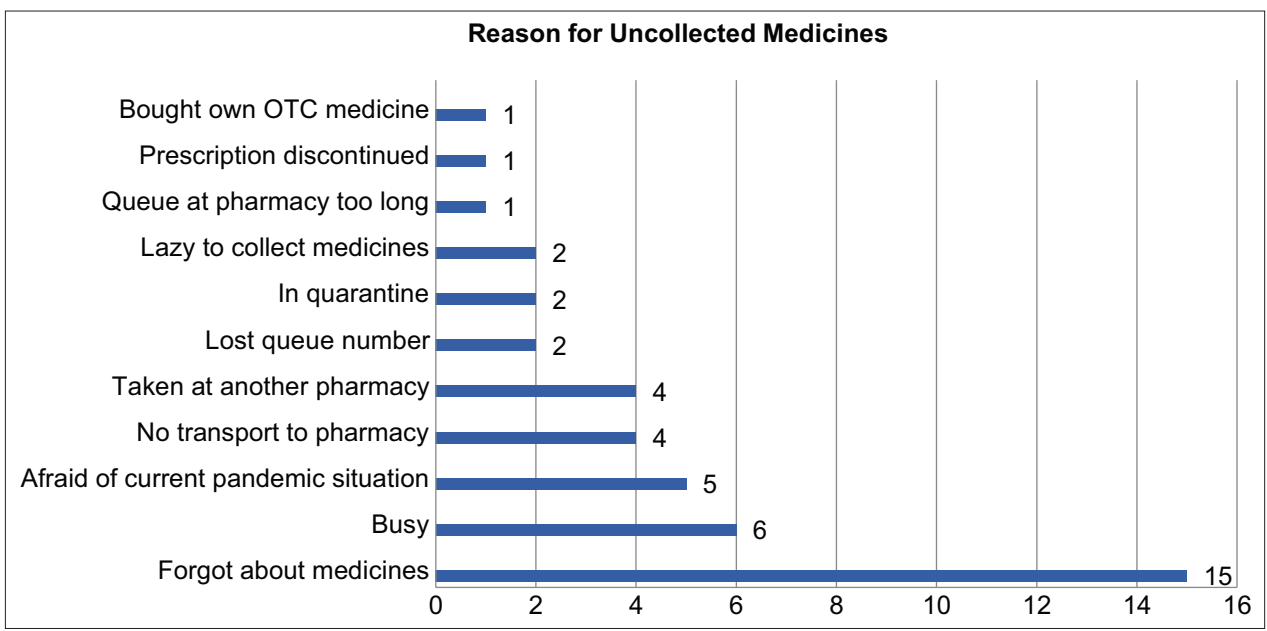

Fig. 3: Reasons why patients did not collect their medicine

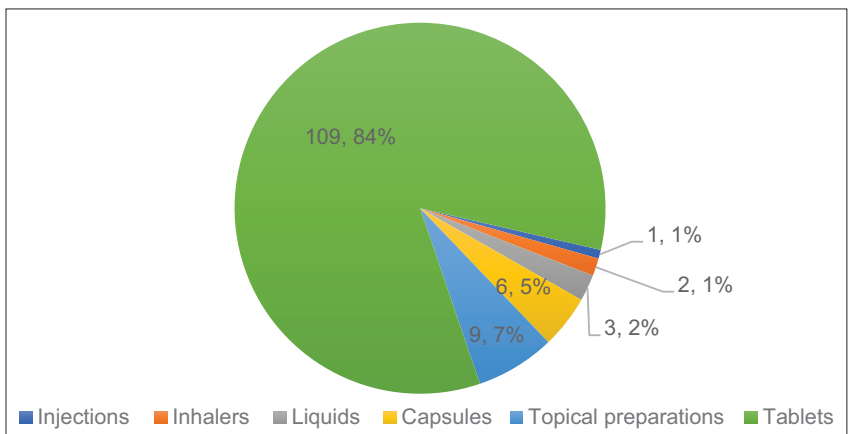

Fig. 4: Form of medicines of the uncollected medicines

in Table 1. The total number of medicines from the 104 prescriptions was 307.

Out of the 104 eligible patients, only 43 were contactable. Their demographic and prescription details are summarized in Table 2. There were $51.2 \%(n=22)$ of females and $48.8 \%(n=21)$ of males, with a mean age of 42 years old. About $32.6 \%(n=14)$ of the patients were in their 40 s and most of them $(n=26)$ had chronic conditions.

In terms of medicines, a total of $58.1 \%(\mathrm{n}=25)$ of the prescriptions contained one or two medicines only, and 31 of the 130 medicines were cardiovascular drugs (Fig. 2). The second most uncollected was ant diabetic drugs $(n=25)$ followed by anti-hyperlipidemia agents $(n=17)$. Medicines in tablet form took up 84\% $(n=109)$ of the medicines. Out of all patients, only one patient paid for their medicines, where the median cost of prescription was BND\$6. The most common reason $(n=15)$ for not collecting medicines was that they forgot to collect them (Fig. 3).

\section{DISCUSSION}

This study measured the rate of uncollected medicines among patients at two community health centers in Brunei. Data collection at BHC was carried out in the first 4 days of the study period before relocating the study site to PAPHMWHB HC. Because the difference between the number of participants at the health care centers was significantly large (89.7\%), no comparison was made between the two study sites.

As shown in Table 1, the rate of uncollected prescriptions was $0.85 \%$ during the study period. This value is similar to a study in Malaysia, where the rate was 0.9\%; and in a Midwestern state in America, where the rate was $0.82 \%[17,18]$. Although the rate is quite low, it can still be improved. From Fig. 2, the uncollected medicines with the highest number are all mostly chronic medicines. In Fig. 4, it shows that most of the patients forgot to collect their medicines followed by patients who were too busy to collect them. These imply that the patients were non-adherent to their medication and this could bring a potential negative health outcome.

Improvement in rates of uncollected medicines

To increase the number of patients picking up their medicines, there needs to be an intervention. Since majority (35\%) of the patients 
in this study forgot about their prescriptions, one method is to set reminders. A common reminder system is using the telephone or mail. In a 2015 study [19], pharmacists gave reminder calls to patients who were 3 days late from picking up their medicines. Results showed that the pickup rate significantly increased within the first 2 weeks. Another study [1] utilized both phone calls and the mail system, where a pharmacist intervened patients with antidiabetic and lipid-lowering medicines. The intervention was more elaborate where there were three parts: Phone consultations around 1 month apart, a summary of the discussion mailed to the patient, and finally a medicine reminder chart, also mailed [1]. Dispensing data showed a difference of $11 \%$ in adherence for refilling their medicines compared to the control group [1]. However, in an older study in 2005 [2], the researchers compared three groups as follows: One had a mailed reminder, another reminded by phone, and the third received no reminders. There were no significant effects on the pickup rates of uncollected medicines [2].

\section{Limitations}

This study has several limitations. The use of convenience sampling, although being advantageous in terms of ease of use, brings a number of biases. Thus, the sample is less likely to represent the whole population. There were also limitations during data collection, where many of the phone numbers of potential participants in the database were either outdated or not listed. Even if there was a valid contact number, patients might have ignored the call as it could have been perceived as spam. COVID-19 pandemic situation is also another factor that has affected the study.

\section{CONCLUSION}

This study recorded a rate of less than $1 \%$ of uncollected prescription rate during the period of 1 month. There was no significant difference in the patient demographic data that could associate a characteristic with uncollected prescription. Further studies should be done to identify interventions that could decrease the number of uncollected medicines.

\section{ACKNOWLEDGMENT}

The authors would like to acknowledge the Department of Pharmaceutical Services, Ministry of Health, Brunei, for allowing us to use their two health centers to conduct this study for this publication.

\section{AUTHORS' CONTRIBUTIONS}

Author Nurolaini Kifli contributed to the study conception, design, and the writing of the manuscript.

Author Najwa Rashidah Ismail contributed to the collection of data, data analysis, and interpretation of data as well as writing the manuscript.

Author Chua Lah Kheng contributed to the study conception and design as well as to the critical revision of the manuscript.

\section{CONFLICTS OF INTEREST}

The author declares that there are no conflicts of interest.

\section{AUTHORS' FUNDING}

No funding was required for this study.

\section{REFERENCES}

1. Lyons I, Barber N, Raynor DK, Wei L. The medicines advice service evaluation (MASE): A randomised controlled trial of a pharmacistled telephone based intervention designed to improve medication adherence. BMJ Qual Saf 2016;25:759-69.

2. Lam WY, Fresco P. Medication adherence measures: An overview. Biomed Res Int 2015;2015:217047.

3. Chancy P, Clifton CL, Branham AR, Hayes HH, Moose JS, Rhodes LA, et al. Implementation of a community pharmacy workflow process to identify and follow up with prescription abandonment. J Am Pharm Assoc 2019;59:S129-35.

4. Shrank WH, Choudhry NK, Fischer MA, Avorn J, Powell M, Schneeweiss S, et al. The epidemiology of prescriptions abandoned at the pharmacy. Ann Intern Med 2010;153:633-40.

5. Ekedahl A, Månsson N. Unclaimed prescriptions after automated prescription transmittals to phamacies. Pharm World Sci 2004;26:26-31

6. Esposito D, Schone E, Williams T, Liu S, CyBulski K, Stapulonis R, et al. Prevalence of unclaimed prescriptions at military pharmacies. J Manag Care Pharm 2008;14:541-52.

7. Kinnaird D, Cox T, Wilson JP. Unclaimed prescriptions in a clinic with computerized prescriber order entry. Am J Heal Pharm 2003;60:1468-70

8. Delate T, Kastendieck D. Assessment of the rates and characteristics of unclaimed prescriptions. J Am Pharm Assoc 2017;57:349-55.

9. Almanie SA, Holdford DA. Economic impact of waste in prescribing, dispensing, and medication consumption in the United States. Value Health 2015;18:A81-2.

10. Tamblyn R, Eguale T, Huang A, Winslade N, Doran P. The incidence and determinants of primary nonadherence with prescribed medication in primary care. Ann Intern Med 2014;160:441-50.

11. Ekedahl A, Oskarsson V, Sundberg B, Gustafsson V, Lundberg T, Gullberg B. Impact of postal and telephone reminders on pick-up rates of unclaimed e-prescriptions. Pharm World Sci 2008;30:503-8.

12. Fischer MA, Stedman MR, Lii J, Vogeli C, Shrank WH, Brookhart MA, et al. Primary medication non-adherence: Analysis of 195, 930 electronic prescriptions. J Gen Intern Med 2010;25:284-90

13. Fischer MA, Choudhry NK, Brill G, Avorn J, Schneeweiss S, Hutchins D, et al. Trouble getting started: Predictors of primary medication nonadherence. Am J Med 2011;124:1081.

14. Wagner TH, Heisler M, Piette JD. Prescription drug co-payments and cost-related medication underuse. Health Econ Policy Law 2008;3:51-67.

15. Simon-Tuval T, Triki N, Chodick G, Greenberg D. Determinants of cost-related nonadherence to medications among chronically Ill patients in maccabi healthcare services, Israel. Value Health Reg Issues 2014;4:41-6

16. Ministry of Health. Brunei Darussalam, Health Information Booklet 2017. Brunei: Ministry of Health; 2017.

17. Kamaruzaman WS. A study of unclaimed prescriptions in hospital universiti Sains Malaysia (HUSM). Med J Malaysia 1995;50:396-400.

18. Doucette WR, Connolly C, Al-Jumaili AA. Estimating the cost of unclaimed electronic prescriptions at an independent pharmacy. J Am Pharm Assoc 2016;56:58-61.

19. Taitel MS, Mu Y, Gooptu A, Lou Y. Impact of late-to-refill reminder calls on medication adherence in the medicare Part D population: Evaluation of a randomized controlled study. Patient Prefer Adherence 2017;11:373-9. 